Original Research Paper

\title{
The Positive Impact of Spirituality on Humanity and Health: An Analytic Article Review
}

\author{
${ }^{1}$ Mansoor Aslamzai and ${ }^{2}$ Sayed Azam Sajid \\ ${ }^{1}$ Department of Neonatology, Kabul University of Medical Science, Afghanistan \\ ${ }^{2}$ Department of Clinical Documentation Specialists, Saints John's Regional Medical Center, USA
}

Article history

Received: 16-09-2020

Revised: $12-12-2020$

Accepted: 04-02-2021

Corresponding Author:

Mansoor Aslamzai, Department of Neonatology, Kabul University of Medical Science, Afghanistan Email: mansooraslamzai@gmail.com

\begin{abstract}
Since virtue is an excellent trait of the human that would be gained throughout one's life, therefore, spiritual education may play a positive role in the development of the mentioned characters. The present study is carried out to find the effects of spiritual education on the achievement of virtues. This study is an analytic article review accomplished in 2020. The articles were searched through Web of Science, PubMed, Scopus, and Google scholar. Based on this analytic article review, spirituality has a positive effect on health and wellbeing; therefore, ethical problems could be improved through spirituality which is the main part of recent psychological interventions. Peace, wellbeing, and happiness in the world are mostly related to the virtues of individuals. The scientific studies found a positive significant relationship between spiritual education and good behavior. The knowledge of two inner sources of thought, feelings, and beliefs in every human entity is a very important component of such education. The inner part (thoughts, feelings, and beliefs) of humans contains positive and negative aspects, also called Heart and Nafs respectively. The heart is responsible for virtues and Nafs is responsible for evils. Every person should look for strengthening oneself heart through spiritual ways. The heart strength mostly via spiritual education and activities conducted by spiritual persons, friends, or teachers. A spiritual person should have effective speeches and good moral characters that influence the heart and mind of people. The awaked heart can positively stimulate the cognitive-affective personality system to perform good characters. The Nafs also can negatively stimulate this system and lead to bad characters. Spiritual education must be available to children and adolescents within school or communities for gaining virtues. Spiritual education is one of the most effective ways of gaining a good moral character. The best spiritual education model described that every speech and activity rooted in the heart effectively activates the cognitive-affective personality system and established admirable behaviors. This kind of education is the best way to have a peaceful and happy world. It also would result in the unity of people of different ethnicities, races, nations, and religions.
\end{abstract}

Keywords: Spiritual Education, Virtues, The Significance of Admirable Character

\section{Introduction}

The term ethics is derived from the Greek word ethos which means custom, habit, character, or disposition. Ethics includes what is good and what is bad for individuals and societies. It is the language of rights and wrongs and covers our rights and responsibilities.
Socrates and Aristotle told the ideal behaviors practice lead to a high level of happiness or wellbeing (Kraut and Richard, 2018; Rich, 2013). Humanitarian ethics is an ethical approach that places great effects on human beings everywhere, without distinctions of any kind. Human requirements are basically the same and revolve around the protection of basic freedoms (Smith, 2019). 
Behavior is the overt verbal or physical movement of the organism generally taken to the environment (Bergner, 2011). The functional relationship exists between the environment and neural or muscular systems responsible for movement (Lazzeri, 2014). The moral character contains the existence or lack of virtues and good behaviors. An internal vital part of the body that gives life to the organism is called the spirit. Spirituality is a global concept that involves belief and obedience to a powerful force called God. Spirituality produces in man qualities such as love, honesty, patience, tolerance, compassion, a sense of detachment, faith, and hope. Reports suggest that some areas of the brain are involved in the establishment of spiritual values and experiences (Hursthouse and Pettigrove, 2018; Verghese, 2008). Cognitive-Affective Personality System (CAPS) is the collection of feels, desires, beliefs, and plans. Once this system activates, it can cause various thoughts, feelings, and behavior. Within the CAPS model, self-regulatory behavior should depend both on regulatory motivation and regulatory competencies (Mischel and Ayduk, 2002; Marcia, 2019). The fetus and newborn babies' surprising activities may relate to spirituality. They have meaningful responses; smile, reaction to pain, response to hypothermia or hyperthermia, and some primitive reflexes such as crossed extension, withdrawal, stepping, rooting and placing. Although fetuses do not take nutrients orally, they develop sucking and swallowing around 34 weeks of gestation. Even fetuses were observed by 4D ultrasonography can smile from the $23^{\text {rd }}$ week of gestation (Goyal et al., 2019; Johnston et al., 2018).

As psychotherapy and talk therapy, Spiritually Augmented Cognitive Behavior Therapy is developed by D'Souza RF. This is a treatment technique, incorporating spiritual values into cognitive behavior therapy. Therefore, cognition and behavior can be improved through spirituality (Verghese, 2008). In the world today, although the field of science, technology, and economy progress enormously but still humans encounter a lot of ethical crises. Unequally development of knowledge versus ethics has advantages and disadvantages. The major examples of hazards are products of atomic weapons, biological weapons, chemical weapons, violence, struggles, national and international wars which often related to ethical problems of individuals and societies (Pamp et al., 2018). Though humans solve the majority of their economic, technological and political problems; but emotional disorders, ethical and moral transgressions are still challenging humanity (Sharma et al., 2009). Biotechnology increases the risk of using biochemical weapons for mass destruction (Xavier, 2014). Even a lot of studies reveal the disadvantages of the internet such as social, ethical, and health problems due to its frequent use (Naikoo et al., 2018). The mentioned ethical problems would agree with us to the statement of
Donahue "we are in throes of giant ethical leap that is essentially embracing for all humankind" (Rich, 2013).

However, there is no universal agreement about admirable and deplorable ethics and behavior; this article denoted such components of ethics and behavior that are acceptable and necessary for all humankind. The majority of people theoretically acknowledge virtues or good moral characters such as real affection, sympathy, compassion, justice, honesty, tolerance, generosity, fidelity and friendship are essential humanitarian ethics. The mentioned moral characters should be enjoyable, sustainable, and influence the soul. In this study, enmity, curse, hate, falsehood, inequality, injustice, intolerance, animosity are accepted as bad ethics for humanity. The main purpose of this analytic article review was to find the role of spiritual education on the development of humanitarian ethics and behaviors such as real affection, sympathy, compassion, justice, honesty, tolerance, generosity, and friendship in human beings. The other objective was to evaluate the significance of the mentioned virtues for happy life and wellbeing. As mentioned before spirituality can improve cognitive and behavior problems. It may have a role to activate the cognitive-affective personality system. Therefore, the current study hypothesized; there may be some spiritual stimulus to activate the cognitive-affective personality system in humankind for the development of virtue or admirable moral characters. The results of the study would be useful for related individuals and organizations informing policy for preventing and solving the problem of unethical behaviors.

\section{Materials and Methods}

This is an analytic article review accomplished in 2020 to evaluate the role of spiritual education for the achievement of virtues or good ethics in humans. Virtues such as real affection, sympathy, compassion, justice, honesty, tolerance, generosity, fidelity, and friendship were accepted as important aspects of humanitarian ethics in this study. The mentioned well moral characters would be sustainable, enjoyable, and influence the soul. The articles were searched through Web of Science, PubMed, Scopus, and Google scholar. Spiritual education, virtues, and the significance of admirable ethics were the key search words. Those articles published after the year 1990 in the English language about spirituality and ethic improvement were selected. Initially, thousands of articles had compatible titles with search items. In the second stage, the abstracts and results of the articles took into consideration. Finally, 50 studies and four books found to be appropriate for the assessment of spiritual education and the improvement of moral characters. Although spirituality has a different meaning, the current study accepted it as attention to inner life (spirit, mental and emotional states) that give 
us a powerful ability, believe in the existence of nonphysical vital force insight oneself, a sense of connection to God that gives the power to gain certain kind of self-knowledge and virtue. The exposure variable was spiritual education and outcome variables were moral characters including real affection, sympathy, compassion, justice, honesty, tolerance, generosity, and friendship. The spiritual education defined as transferring and establishing outcome variables through speeches, meetings, and activities by the spiritual person. Anyone who has enough virtues or moral characters and their speeches and activities influence the mind, heart, and spirit of humans, called spiritual persons. In other words, the spiritual person could be able to improve the bad behavior and characters of their majority audients.

\section{Results}

\section{The Significance of Virtues or Admirable Moral Characters}

\section{Religious and Philosophical View}

There are a lot of verses in Quran regard to virtues. God creates the human and evaluates which one performs virtues. God loves the virtuous person (Abou El Fadl, 2017). Those who have affection for God, God has also affection for them. Tell them if you love God, follow the prophet so that God also loves you, and forgives your sins. God is Forgiving and Merciful. Merciful God puts friendship for those who believe in God and do virtues (Koopaee et al., 2016).

Buddha quotes about good moral characters: In the end, only three things matter: How much you loved, how gently you lived, and how gracefully you let go of things not meant for you. As rain falls equally on the just and the unjust, do not burden your heart with judgments but rain your kindness equally on all (Buddha Quotes, 2020). In Buddhist philosophy four ethical virtues are important for wellbeing; compassion, loving-kindness, sympathetic joy, and equanimity (Rich, 2013).

Some verses about well moral characters in the Bible: Anyone who does not love does not know God, because God is love. For God so loved the world. Greater love has no one than this that someone lay down his life for his friends. There is no fear in love, but perfect love casts out fear. Watch over your heart with all diligence, for from it flow the springs of life. Trust in the Lord with all your heart and lean not on your own understanding. Above all, love each other deeply, because love covers a multitude of sins. Who comfort as in all our trouble, so that we comfort those in any trouble with the comfort we ourselves receive from God. One who is faithful in a very little is also faithful in much, and one who is dishonest in a very little is also dishonest in much. One who has unreliable friends soon comes to ruin, but there is a friend who sticks closer than a brother (Wellman, 2015; Hart, 2019). Socrates (470-399 B.C) is known as the father of ethics. He advanced some unusual ideas about how to be happy in life. His moral beliefs seem at best peculiar till now. Socrates believed that a good life is a need to be happy. Moral virtues are necessary for the individual and community, also enough to guarantee our happiness. He stressed the care of one's soul as well as possible. His inquiry, dialogues, and discursive method did not find favor which led enemies to put Socrates on trial (Rahman and Mahmud, 2002; Haybron, 2006). According to the theory of Marx, Mill, Rawls, and situationists; the character can be molded by antecedent circumstances. Marx by economic structures; Mill by paid work and political life; Rawls by the institutions (Haybron, 2006; Marcia, 2019). Postmodernism has begun around 1950, after the end of World War II. Postmodernism defined as a modern change in philosophy that rejects the optimistic view that scientific methods and reasons will improve humanity. People who live according to postmodern philosophy acknowledge that reality is constantly changing and scientific investigation cannot guide human behavior, relationships, and life (Haybron, 2006; Rich, 2013). Recent philosophical empirical studies conducted by social and cognitive psychologists have developed a "cognitive-affective personality system" so-called CAPS. The model views the structure of personality as the organization of relationships among "cognitive-affective units". These units are collections of feel, desire, belief, and plan. Once this system activates it can cause various thoughts, feelings, and behavior in a stable pattern.

In the CAPS model, self-regulatory behavior should depend both on regulatory motivation and regulatory competencies (Mischel and Ayduk, 2002). Psychotherapy, psychoeducation, psychosocial intervention program, cognitive behavior therapy, behavior activation, and spiritually augmented cognitive behavior therapy are recent advances in the management of psychological and mental health. These approaches reveal the role of science and research on the improvement of the mind, feeling, and behavior of humans. Behavior activation is a type of therapeutic intervention that helping people to plan more activities they actually enjoy doing and develop their social skills (Selva, 2019; Delgadillo and Groom, 2017; Verghese, 2008). It is essential to promote the development of friendly relations between nations (UN, 2012).

\section{Health and Wellbeing View}

The World Health Organization defines health as a state of complete physical, mental, and social well-being and not merely the absence of disease. Most would agree with this statement, but over the years, it has been largely a slogan (Park et al., 2016). The absence of mental disorder does not mean mental health, but the 
feelings and thoughts about one's and other's life are also parts of mental health. The virtues and good behaviors mostly related to mental health (Ghosh et al., 2020). Torka (2019) accomplished an article review. He concluded the honesty must be considered as a distinctive and universal virtue. Honesty towards ourselves and others is an important factor for genuine happiness. Both types of honesty are crucial for modifying unhealthy thoughts and behaviors that are a stumbling block to genuine happiness.

Veenhoven (2008) performed a synthetic analysis of 30 follow-up studies on happiness. He defines happiness as the overall appreciation of one's life-as-a-whole, or how much one likes the life one lives. The conclusion showed happy people live longer, probably because happiness protects physical health. Therefore, public health should provide chances of greater happiness for a great number of humans through policies. The happy people are more likely to endorse social values such as solidarity, tolerance, and love. Also, a happy human tends to be less materialistic than unhappy.

Mahboube et al. (2019) conducted a crossed sectional study at Tehran University of Medical and Health Services. They emphasized that an effective attitude and collaboration between doctors and nurses is the main factor in achieving positive medical results. Doctors and nurses should learn the ethic of helping in the course of their academic education. Social inequalities have more impact on the mental health of females than males (Yu, 2018). Amati et al. (2018) conducted a study to evaluate the association of social relationships and life satisfaction. The research data was obtained from the multipurpose survey "Aspects of Daily Life," collected by the Italian National Statistical Institute in 2012. It was a large sample survey that interviews a sample of approximately 50,000 people aged 18-64 years old in about 20,000 households. The results showed that both having/meeting friends and good-quality friendship relations are important to overall life satisfaction. Individuals may benefit from positive interactions with friends, which are a part of an individual's society. Trusting other people and having a positive attitude increase the probability of having high life satisfaction.

\section{The Role of Spirituality on the Development of Virtues and Good Moral Characters}

Spirituality is a globally acknowledged concept that involves belief and obedience to a powerful force called God, who controls the universe and the destiny of man. It also consists of deep attention to inner life and relation to nonphysical vital power insight oneself. Spirituality crosses the cultures and produces qualities in humans such as love, honesty, patience, tolerance, compassion, friendship, faith, and hope. For the establishment of spiritual values and experiences; reports reveal some areas of the brain would be involved (Verghese, 2008). According to the study of Burkhardt (2010) secularization has been dominant for a long time, now leaving the place for spirituality. Ayoun et al. (2015) the study revealed the effect of religion on ethical behaviors and the relationship between spirituality and ethics. A lot of surprising and meaningful behavior in newborns and fetuses seem to be related to spirituality. Neonates can demonstrate their happiness and discomfort through smiles and cry respectively. Even fetuses were observed by $4 \mathrm{D}$ ultrasonography, the smile from the 23rd week of gestation. Sucking and swallowing usually developed after 32 weeks of gestation in fetuses. In intrauterine live away from the human's environment, who learn the fetuses these behaviors? Reaction to pain, response to hypothermia or hyperthermia, and some primitive reflexes such as crossed extension, withdrawal, stepping, rooting, and placing are other patterns of neonatal behavior (Goyal et al., 2019; Johnston et al., 2018).

Effective teaching has four aces; outcomes, clarity, enthusiasm, and engagement (Bulger et al., 2002). The teachers' positive attitudes have positively influenced students' personality as well as their live performances (Ulug et al., 2011). The best education approach should be student-centered along with teacher-centered plus educational planning and previous readiness. A good education method would solve the students' questions and motivates them to learn (Bidabadi et al., 2016). If we want to reform schooling and education, we must acknowledge humanity's spiritual nature. Several important psychologists accepted humankind's spiritual nature as part of human behavior. Religion, science, and philosophy have valuable contributions to the understanding of what it means to be human (Huitt, 2000). Experimental learning opportunities for good moral characters must be available to children and adolescents within school or communities. The character education program should focus on the internal processes of knowing, thinking, judging, feeling, and expressing empathy (Vessels and Huitt, 2005).

Every human has two inner parts (thoughts, feelings and beliefs); one for virtues or good characters and the other for evils or bad characters. In other words, there are two sources in the internal part of a human. One is called Heart and the other is Nafs. The heart is the source of virtues and Nafs is the source of evils. These sources strength by various methods. From these two source, if everyone is stronger the related characters would be developed in human beings. If the Heart becomes stronger; true virtues such as compassion, royalty, affection, sympathy, justice, honesty, tolerance, generosity, and friendship would be established. If the Nafs get stronger; evils like enmity, curse, anger, hate, falsehood, inequality, injustice, intolerance, animosity would be prominent. A spiritual or complete person can prohibit the Nafs, awake the Heart, and flight to the 
Spirit. When a person becomes angry his speeches and activities can influence the mind and soul of others; therefore, a spiritual person should have effective speeches and characters that influence the heart and mind of people. They also should have the ability to improve the ethic and behavior of the human, stimulate their heart, and establish good moral characters in them. Prostration, worship, and virtue fortify spirituality. Such improvement, initially achieve in individuals goes to families and finally involves the societies (Baba Sahib, 2010).

Since the individual's evil can influence the source of evil in others and persuade them for bad characters, as evident in religious and non-religious people all over the world; the human's true virtues must stimulate the source of virtues in the soul of others to persuade them for good characters. Therefore, any speech or activity rooted in the heart has the effects to motivate his/her and others' hearts to perform virtues. The speech of the heart hears by the heart and the speech of the Nafs hears by the Nafs. Such knowledge and performance are a type of spiritual education that required for all religious and non-religious humankind (Baba Sahib, 2009).

Spirituality and mental health has one similar goal; liberation from mental and physical suffering. A lot of psychotherapists believed that psychotherapy by itself is a spiritual activity. Spirituality is being increasingly recognized in the mental health field as having a huge potential for improving the mental, physical and ethical problems of individuals and society (Sharma et al., 2009). Cognitive-behavioral therapy is a useful management of mental and psychological disorders. This is a psychological approach to promote good mental health. This kind of psychotherapy gives the power to feel better about oneself, reduce stress, cope with complicated relationships, grief, and common life challenges (Irie et al., 2019). D'Souza RF describes a new psychotherapeutic method, which is called Spiritually Augmented Cognitive Behavior Therapy (SACBT). This is a treatment technique, incorporating spiritual values to cognitive behavior therapy, which was developed and promoted at the University of Sydney (Verghese, 2008). Meditation is a spiritual and healing activity. It is scientifically defined as a practice that self-regulates the mind and body by engaging an inner attentional set and body relaxation. The medical benefits of meditation include psychological disorders, hypertension, cardiovascular diseases, chronic pain, and other life problems (Dakwar and Levin, 2009). Meditation used for spiritual development, concentration, growth of inner peace, getting positive emotions such as happiness and love, and ignoring negative emotions such as anger or fear (Anifowose, 2017). Behavioral activation is another type of therapeutic intervention that helping people to plan more activities they actually enjoy doing and develop their social skills (Selva, 2019).
Recent researches performed with modern scientific methods in various disciplines including psychology, psychiatry, medicine, neuroscience, theology, gerontology, and nursing have found evidence that spirituality helps in the management of various mental and physical illnesses. Reduced levels of anxiety associated with spiritual activity have been found in various populations. Yogic treatments can effectively cure and prevent a lot of diseases ranging from hypertension, asthma, heart disease, cancer, multiple sclerosis, and diabetes. Spirituality helps depressive patients to regain the meaning or a purpose in their life, which they had lost due to their illness (Sharma et al., 2009). A study found that for every 10 -fold increase in a person's intrinsic religiosity, there was a $70 \%$ increase in recovery from depressive symptoms (Koenig et al., 1998). Spiritual coping strategies such as prayer and meditation could be useful for the management of pain in people with chronic low back. The coping techniques for pain relief can be achieved by having strong religious well-being; the strength of spiritual beliefs is a beneficial way to influence healing (Anifowose, 2017). Researches in contemporary psychology have reached a similar conclusion. It has been found that life satisfaction correlates positively with mystical experiences (Kass et al., 1991), and people who have had spiritual experiences report tremendous positive feelings as compared to others (Kennedy et al., 1994). Vitorino et al. (2018) performed a crossed sectional online study including 1252 participants aged more than $18 y$ old. The participants with high spirituality and high religiousness had more psychological and social relationships and optimism and happiness. Göçer and Özğan (2018) performed a literature review at the University of Gaziantep, Turkey. The research concluded that there is an increasing positive consensus on the relationship between spirituality and ethics in empirically tested studies. Spirituality or spiritual life could be a strong predictor of ethical issues and decisions at work. Spirituality has an important role in the sustainability and solution of new world problems. Therefore, this would be no wonder that spirituality and ethics can play important roles in the wellbeing of a human and society especially in the coming decades. There is a significant relationship between spirituality with work performance, leadership, organization commitment, and life satisfaction (Petchsawang and Duchon, 2012; Fry et al., 2017). Recent research reports strongly emphasized that religion and spirituality help patients cope with the stresses in their life. Many psychiatrists now have the opinion that religion and spirituality are important for their patients. The importance of spirituality in mental health is now widely accepted (Verghese, 2008). The role of science would be crucial in raising the spiritual and moral characters of future society (Yachina, 2015). 


\section{Discussion}

The current study was conducted to reveal the role of spiritual education on the establishment of humanitarian ethics and behaviors including virtues and good moral characters. Ethics is the language of rights and wrongs; it includes what is good and what is bad for individuals and societies. Virtue or admirable moral character is an important part of a good ethic (Rich, 2013). Feelings and thoughts about one's and other's life are parts of mental health. Therefore, mental health is not just the absence of mental disorder. The virtues and good behaviors mostly related to mental health (Ghosh et al., 2020). Islam, Judaism, Buddhism and Hinduism highly recommend virtues for their followers. From the view of all religions, good moral characters are the most valuable issue for the wellbeing of humanity (Abou El Fadl, 2017; Koopaee et al., 2016; Buddha Quotes, 2020; Rich, 2013; Wellman, 2015). All religions and most psychologists, researchers, and philosophies believed that peace, wellbeing, and happiness in the world largely related to internal peace, admirable moral characters, and virtues of individuals. Despite the vital significance of virtues, the majority of humans have no access to enough moral character that is required for universal wellbeing, happiness, and peace. Ancients and postmodern philosophies have different views on the importance and methods of gaining virtues. Socrates believed, virtue is the most important factor in the wellbeing of humans and it can be learned like knowledge (Rahman and Mahmud, 2002). Based on Marx, Mill, Rawls, and situationists theories, the character can be molded by antecedent circumstances. According to these theories of Marx, Mill, and Rawl's characters would be improved via economic structures, political life, and institutions respectively (Marcia, 2019). Such theories raised troubling questions; if our character is the result of social and political institutions beyond our control, then perhaps we couldn't control our characters at all and becoming decent which is not a real possibility. Also, psychological experimental studies condemn such theory. Although not consistent with the recent results of scientific researches, postmodernism as a modern movement in philosophy rejects the optimistic view that science and reason will improve humanity (Marcia, 2019). On the other hand, if the good character is based on naturally occurring psychological responses, then most people should be able to become better and to be responsible for actions that express their character. Now a lot of studies established the role of spirituality and science on the improvement of behaviors, characters, and attitudes. Spirituality is a deep attention to inner life or a sense of relation to nonphysical vital power insight oneself. It produces love, honesty, patience, tolerance, compassion, friendship, faith, and hope in humankind. Some areas of the brain would be involved in the establishment of spiritual values (Verghese, 2008). Spirituality has been identified as an important factor in overall health and well-being (Rego and Nunes, 2019). The Covid-19 pandemic produced high morbidity, mortality, and stress to human beings (Fauci et al., 2020). At the moment this viral disease has no specific treatment and vaccine, therefore spirituality may cope with the stresses due to this tragedy and also act as a preventive measure. Recently cognitive-affective personality system has been developed through empirical studies. These units are collections of disposition, belief, feel, and desire. Once this system activates it can cause various thoughts, feelings, and behavior to be formed. (Mischel and Ayduk, 2002). So on the bases of this study, the activation of the cognitive-affective personality system would develop admirable characters.

Psychotherapy, psycho-education, psychosocial intervention programs, behavior activation, spiritually augmented cognitive behavior therapy and meditation are recent advances in the management of psychological and mental diseases. (Delgadillo and Groom, 2017; Selva, 2019; Verghese, 2008; Dakwar and Levin, 2009; Anifowose, 2017). All these methods significantly manage mental and psychological disorders; therefore, ethical problems could be improved through spirituality which is the main part of such interventions. The relation between spirituality and behavior demonstrated even in the intrauterine life of the fetus. The fetus and newborn babies' surprising activities may have related to spirituality. Although fetuses have no need to take nutrients via mouth; sucking and swallowing develop around 34 weeks of gestation. These activities prepare the fetus for extrauterine life. Fetuses can smile from the 23rd week of gestation. In intrauterine live away from the humans' environment, who learn the fetuses these behaviors? (Goyal et al., 2019; Johnston et al., 2018). The positive significant relationship between spirituality and virtues as evident in scientific studies strongly supports the role of spiritual education on the achievement of humanitarian ethics and good moral characters.

Spiritual education described by Baba Sahib (2010) includes the real meaning of spirituality. This model provides the facility for everyone to have analytic inner attention and assess oneself daily character, behavior, and attitude. Based on this method everyone can judge their true virtue and evil characters, increase their virtue via the strength of the heart. The knowledge of two inner parts (thoughts, feelings and beliefs) in every human entity is a very important component of such education. Inner part (thoughts, feelings and beliefs) of humans contains positive and negative aspects, also called Heart and Nafs respectively.

The heart is responsible for virtues and Nafs is responsible for evils. Every person should look for strengthening oneself heart through spiritual ways. In 
this way, deep inner attention is necessary for everyone to evaluate oneself characters and motivate them for gaining virtues. The heart strength mostly via spiritual education conducted by spiritual persons or teachers. A spiritual person should have effective speeches and good moral characters that influence the heart and mind of people. They also should be able to improve the ethic and behavior of the human, stimulate their heart, and develop good moral characters in them. Such improvement, initially establish in individuals goes to families and finally involves the societies. The spiritual education model of Baba Sahib, 2010 is consistent with the scientific findings of Mischel and Ayduk (2002). The heart positively stimulates the cognitive-affective personality system to perform good feelings, thoughts, and characters. The Nafs also negatively stimulates this system, and lead to bad feelings, thoughts and characters. Baba Sahib model of spirituality practices in many countries of Asia, Europe, America, and Australia with excellent outcomes of wellbeing and happiness.

Spiritual education must have the four aces of effective teaching as described by Bulger et al. (2002) outcomes, clarity, enthusiasm, and engagement. The teachers' positive attitudes have positively influenced students' personality as well as their live performances (Ulug et al., 2011). Therefore, spiritual teachers' or persons' attitudes must influence the audiences' personalities, behaviors, and live performances. Such education would include effective approaches of student and teacher-based, solve the students' questions, and motivate them to learn.

According to the study of Huitt, the spiritual nature of humanity should be included in the teaching program of schools (Huitt, 2000). Spiritual education must be available to children, adolescents, and adults within school or communities for gaining virtues. Such an education program should focus on the internal processes of knowing, thinking, judging, feeling and expressing empathy (Vessels and Huitt, 2005).

\section{Conclusion}

The importance of good moral characters for the wellbeing and happiness of humans' life is demonstrated by various religions, philosophies, and researches. The role of spirituality observes from intrauterine life on the behavior of the fetus and then it influences the behavior of neonates, infants, children, adolescents, and adults. There are strong data that spirituality and virtues have a positive significant relationship with each other; and both of them play a crucial role in the improvement of physical and mental health, life satisfaction, social relationship, work performance, organization commitment, and leadership. Spirituality may also have a preventive and therapeutic role in the management of health crises like the Covid-19 pandemic. Therefore, the studies denoted that opportunities must be available within schools, universities, and communities for children, adolescents, and adults to learn admirable moral characters. Based on this analytic review; spiritual education is one of the most effective ways for learning, gaining, and performing excellent traits and virtues. The best spiritual education model established by Baba Sahib recently, the speeches and activities rooted in the heart effectively stimulate and activate the cognitiveaffective personality system and establish admirable behaviors. Everyone should search for their spiritual heart and find a way for its strength. Spiritual virtue persons, friends, teachers, or leaders can transfer or give heart rooted virtues via speeches and activities to other hearts. Virtues, worship, and prostration augment spirituality. The mentioned education can develop spiritual friendship between individuals of families, organizations, and societies. Spiritually educated peoples' and families' relationships and meetings are required for the strength of better moral characters. Such education and relation is the best way to have a peaceful and happy world. People with different ethnicity, race, nationality, and religious believers would become united through this view.

\section{Acknowledgment}

We gratefully acknowledge who performed their humanitarian responsibilities for the improvement of the moral characters of the human being and also the authors who published articles or books in this field.

\section{Funding}

No funding was getting for this analytic article review. The authors performed this research for their humanitarian responsibilities.

\section{Authors' Contributions}

All authors equally contributed in this study.

\section{Ethic}

The analytic article review was approved in the Department of Neonatology, Kabul University of Medical Science (protocol no. 6 and date 19/2/2020).

\section{References}

Abou El Fadl, K. (2017). Qur'anic ethics and Islamic law. Journal of Islamic Ethics, 1(1-2), 7-28.

Amati, V., Meggiolaro, S., Rivellini, G., \& Zaccarin, S. (2018). Social relations and life satisfaction: the role of friends. Genus, 74(1), 7.

Anifowose, B. G. (2017). Integration of Spirituality into Chronic Low Back Pain Management in Adult Patients (Doctoral dissertation, Grand Canyon University). 
Ayoun, B., Rowe, L., \& Yassine, F. (2015). Is workplace spirituality associated with business ethics? International journal of Contemporary hospitality management.

Baba Sahib, A.M. (2009). The Motivator of Human Entity. Kabul.

Baba Sahib, A.M. (2010). The Mirror of Evil and Virtue of Human Entity. Kabul.

Bergner, R. M. (2011). What is behavior? And so what? New ideas in psychology, 29(2), 147-155.

Bidabadi, N. S., ISFAHANI, A. N., Rouhollahi, A., \& Khalili, R. (2016). Effective teaching methods in higher education: requirements and barriers. Journal of advances in medical education \& professionalism, 4(4), 170.

Bright Drop. (2020). 33 Deep Buddha Quotes on Love, Life and Happiness. Bright Drop. https://brightdrops.com/deep-buddha-quotes

Bulger, S. M., Mohr, D. J., \& Richard, T. (2002). Stack the Deck in Favor of Your Students by Using the Four Aces of Effective Teaching.". The Journal of Effective Teaching, 5(2), 512-527. https://uncw.edu/jet/articles/bulger/

Burkhardt, H. (2010). Spirituality and Ethics. European Journal of Theology, 19(1).

Dakwar, E., \& Levin, F. R. (2009). The emerging role of meditation in addressing psychiatric illness, with a focus on substance use disorders. Harvard Review of Psychiatry, 17(4), 254-267.

Delgadillo, J., \& Groom, M. (2017). Using psychoeducation and role induction to improve completion rates in cognitive behavioural therapy. Behavioural and Cognitive Psychotherapy, 45(2), 170-184.

Fauci, A. S., Lane, H. C., \& Redfield, R. R. (2020). Covid-19-navigating the uncharted.

Fry, L. W., Latham, J. R., Clinebell, S. K., \& Krahnke, K. (2017). Spiritual leadership as a model for performance excellence: a study of Baldrige award recipients. Journal of Management, Spirituality \& Religion, 14(1), 22-47.

Ghosh, D., Adhikari, S., \& Das, R. (2020). To Explore the Mental Health of our School Teachers. Asian Journal of Science and Technology, 11(01), 10634-10636.

Göçer, A., \& Özğan, H. (2018). Spirituality and Ethics: A Literature Review. Gaziantep University Journal of Social Sciences, 17, 58-65.

Goyal, N. K., Suhrie, K. R., \& Tabbah, S. M. (2019). The Newborn Infants and Fetus. In: Kliegman R.M., J. W. ST Geme, N. J. Blum, Nelson Textbook of Pediatrics, (pp: 3741-3822). Lange, Philadelphia, ISBN: 978-0-323-52950-1.

Hart, R. (2019). Beautiful Bible Verses About Friendship. https://www.ryanhart.org/friendship-bible-verses/.
Haybron, D. M. (2006). Well-being and virtue. J. Ethics \& Soc. Phil., 2, i.

Huitt, W. (2000). The spiritual nature of a human being. Educational Psychology Interactive.

Hursthouse, R., \& Pettigrove, G. (2018). Virtue Ethics. The Stanford Encyclopedia of Philosophy. https://plato.stanford.edu/archives/win2018/entries/e thics-virtue/

Irie, T., Yokomitsu, K., \& Sakano, Y. (2019). Relationship between cognitive behavioral variables and mental health status among university students: A meta-analysis. PloS one, 14(9), e0223310.

Johnston, J. H., Whitelaw, A., Osredkar, D., \& Thoresen, M. (2018). Fetal Imaging and Neonatal Neurology: In Averys Neonatology, MacDonald M.G., M.M. K. Seshia, Philadelphia, Ch. 12, PP 330-335 Ch, 46, pp. 2118-2124. ISBN/ISSN: 9781451192681

Kass, J. D., Friedman, R., Leserman, J., Zuttermeister, P. C., \& Benson, H. (1991). Health outcomes and a new index of spiritual experience. Journal for the Scientific Study of Religion, 203-211.

Kennedy, J. E., Kanthamani, H., \& Palmer, J. (1994). Psychic and spiritual experiences, health, well-being and meaning in life. Journal of Parapsychology, 58(4), 353-383.

Koenig, H. G., George, L. K., \& Peterson, B. L. (1998). Religiosity and remission of depression in medically ill older patients. American Journal of Psychiatry, 155(4), 536-542.

Koopaee, H. I., \& Hosseini, S. M. B. (2016). Investigation of love and affection (In verses of Quran, Nahjolbalagheh, Narrations of Innocent Imams (PEACE BE UPON THEM) and poetry of poets). International Journal of Humanities and Cultural Studies (IJHCS) ISSN 2356-5926, 1(1), 2026-2039.

Kraut, \& Richard (2018). Aristotle's Ethics. The Stanford Encyclopedia of Philosophy.

https://plato.stanford.edu/archives/sum2018/entries/ aristotle-ethics/

Lazzeri, F. (2014). On defining behavior: Some notes. Behavior \& Philosophy, 42.

Mahboube, L., Talebi, E., Porouhan, P., Orak, R. J., \& Farahani, M. A. (2019). Comparing the attitude of doctors and nurses toward factor of collaborative relationships. Journal of Family Medicine and Primary Care, 8(10), 3263.

Marcia, H. (2019). Moral Character. The Stanford Encyclopedia of Philosophy. https://plato.stanford.edu/archives/sum2019/entries/ moral-character

Mischel, W., \& Ayduk, O. (2002). Self-regulation in a cognitive--affective personality system: Attentional control in the Service of the Self. Self and Identity, 1(2), 113-120. 
Naikoo, A., Thakur, S., Guroo, A., \& Lone, A. (2018). Development of society under the modern technology-A review. Scholedge International Journal of Business Policy \& Governance, 5(1), 1-8.

Pamp, O., Rudolph, L., Thurner, P. W., Mehltretter, A., \& Primus, S. (2018). The build-up of coercive capacities: Arms imports and the outbreak of violent intrastate conflicts. Journal of Peace Research, 55(4), 430-444.

Park, N., Peterson, C., Szvarca, D., Vander Molen, R. J., Kim, E. S., \& Collon, K. (2016). Positive psychology and physical health: Research and applications. American journal of lifestyle medicine, 10(3), 200-206.

Petchsawang, P., \& Duchon, D. (2012). Workplace spirituality, meditation and work performance. Journal of Management, Spirituality \& Religion, 9(2), 189-208.

Rahman, R., \& Mahmud, M. N. (2002). Socrates: His ethical and Political Beliefs plus Their Relevance on Certain Legal Concepts. Malayan Law Journal. https://www.researchgate.net/publication/296676262.

Rego, F., \& Nunes, R. (2019). The interface between psychology and spirituality in palliative care.

Rich, K. L. (2013). Introduction to ethics. Nursing ethics: Across the curriculum and into practice, 1.

Selva, J., (2019). Behavioral Activation: Behavioral Therapy for Depression Treatment. Positive Psychology.

https://positivepsychology.com/behaviouralactivation-therapy-treating-depression/

Sharma, P., Charak, R., \& Sharma, V. (2009). Contemporary perspectives on spirituality and mental health. Indian Journal of Psychological Medicine, 31(1), 16.

Smith, T. (2019). Ethical Behaviour and Moral Decision Making within Virtual Worlds (Doctoral dissertation, University of Lincoln).
Torka, N. (2019). Honesty and genuine happiness: Or why soft healers make stinking wounds (Dutch proverb). British Journal of Guidance \& Counselling, 47(2), 200-209.

Ulug, M., Ozden, M. S., \& Eryilmaz, A. (2011). The effects of teachers' attitudes on students' personality and performance. Procedia-Social and Behavioral Sciences, 30, 738-742.

UN. (2012). The Universal Declaration of Human Rights. United Nation. http://www.un.org/en/documents/udhr/

Veenhoven, R. (2008). Healthy happiness: Effects of happiness on physical health and the consequences for preventive health care. Journal of Happiness Studies, 9(3), 449-469.

Verghese, A. (2008). Spirituality and mental health. Indian Journal of Psychiatry, 50(4), 233.

Vessels, G., \& Huitt, W. (2005, March). Moral and character development. In National Youth at Risk Conference, Savannah, GA, March (pp. 8-10).

Vitorino, L. M., Lucchetti, G., Leão, F. C., Vallada, H., \& Peres, M. F. P. (2018). The association between spirituality and religiousness and mental health. Scientific reports, 8(1), 1-9.

Wellman, J. (2015). What Does Virtue Mean? A Biblical Definition of Virtue or Virtuous. Christian Crier. https://www.patheos.com/blogs/christiancrier/2015/ 08/19/what-does-virtue-mean-a-biblical-definitionof-virtue-or-virtuous/

Xavier, E. A. (2014). Prions: The danger of biochemical weapons. Food Science and Technology, 34(3), 433-440.

Yachina, N. (2015). The Problem of spiritual and moral formation of personality. Procedia-Social and Behavioral Sciences, 197, 1575-1579.

$\mathrm{Yu}$, S. (2018). Uncovering the hidden impacts of inequality on mental health: A global study. Translational psychiatry, 8(1), 1-10. 